chapter on body composition and anthropometry in children in which the relatively new technique of bioelectrical impedance measurement is described. There are a couple of chapters on anthropometry and physical performance and fitness. The final chapter is on the uses of anthropometry in the US armed forces.

Although this is not a book to recommend for the bookshelf of every public health physician, it will be useful to those involved in research relating to the measurement of human characteristics.

JANET CADE

Public Health and Epidemiology, University of Manchester.

\section{Origins of Regional Differences in Mortality from Ischaemic Heart Disease in Finland. Seppo Koskinen.} National Research and Development Centre for Welfare and Health. Research Reports No 41. (Pp 204; price f15). Helsinki: Finland, 1995. ISBN 951-47-9600-4.

The pioneering epidemiological research in ischaemic heart disease (IHD) in Finland is well recognised and this small book provides a useful contribution to the specialist literature. The primary data set covers the period $1971-85$, the age group 35 to 64 years of age, and links mortality and census data. The author found that region of birth was much more closely linked with mortality from IHD than was region of residence. The author suggests that this provides some support for the hypothesis that this excess mortality is due to the poverty of the childhood environment, although genetic factors are acknowledged as an alternative or additional explanation.

This book contains no original epidemiological survey data and the readers interested in a broader epidemiological view should also read a recently published account of the North Karelia project (The North Karelia Project. 20 Year Results and Experiences. Eds Puska P, Tuomilehto J, Nissinen A, Vartiainen E. The National Public Health Institute (KTL), Helsinki, Finland 1995. ISBN: 951-53-0549-7). This summarises the considerable public health achievements in reducing the mortality from cardiovascular disease in the whole of Finland and provides a bibliography of the important series of papers published by the authors linking changes in risk factors with trends in IHD mortality.

JOHN W G YARNELL Department of Epidemiology and Public Health, Queen's University of Belfast, Belfast.

Statistics and Clinical Practice. David Coggon (Pp 116; $£ 10.95)$ London: BMJ Publishing Group, 1995 ISBN 0-7279-0907-X.

This handily sized book is aimed at those doctors and medical students who wish a brief introduction to basic statistical analysis as well as the basic principles underlying more complicated analytical techniques.

The book is well laid out with numerous worked examples to illustrate the points discussed. In addition, there are questions at the end of each chapter so that readers may test their understanding of the contents. The first three chapters, as with most books of this type, deal with discussing types of data and how to summarise univariate, bivariate, and multivariate data. Of particular use, however, are the subsequent chapters, which provide an introduction to probability, and the principles behind hypothesis testing, confidence intervals, and a calculation of statistical power. The author highlights important aspects for the clinician in these topics and provides clear explanations of the relationships - eg, between confidence intervals and $p$ values or confidence intervals and sample size. A brief introduction to statistical modelling is provided, with a worked example on multiple linear regression and discussion of survival analysis. The book concludes with a chapter on the interpretation of statistical analysis incorporating discussion of bias, chance, and of meta-analysis.

This book will be particularly useful to those who, either by choice or by necessity, find themselves conducing studies, but who have little statistical experience. It will enable them to understand the principles behind the planning of their experiment, to carry out a preliminary data analysis, and to benefit more from the additional expertise to be provided by their local medical statistician.

GARY MACFARLANE ARC Epidemiology Research Unit, University of Manchester.

Epidemiology of Work Related Diseases. Ed J Corbett McDonald (Pp 498; £49.95) London: BMJ Publishing Group, 1995. ISBN 0-7279-0856-1.

This book, which includes contributions from 23 authors, is a very welcome addition to the literature on occupational epidemiology. It is divided into two main sections, the first considers the available information on aspects of work in relation to disease. Four chapters are devoted to occupational cancer considering the effects of metals and chemicals, ionising radiation, electromagnetic fields, and mineral dust and fibres. The authors of these chapters have provided a very thorough review of the most important aspects of these topics. The remaining chapters of this first section are devoted to non-malignant disease and, taking as an example the chapter on musculo-skeletal diseases, the reader is provided with a detailed yet concise summary of the evidence relating aspects of employment to disorders of the back, lower limb, and upper limb. There is also a comprehensive list of over 100 references at the end of this chapter, allowing the reader to research whichever particular aspect of the subject interests him or her, in greater detail. A particularly interesting chapter in this section analyses the evidence linking stress at work to specific diseases as well as measures of mental health and general well being.

The second section of the book is devoted to methodology in occupational epidemiology. This will be particularly useful for students, since a thorough grounding is given of the design of studies, assessment of exposure, measurement of outcome, and evaluation of preventive measures. There is also a chapter on analysis and interpretation and although it provides a good genera introduction, it would require those unfamiliar with the techniques described to use alternative textual sources before being able to implement them in practice. Overall, this is a thoroughly recommendable textbook both for those working in the field of occupationa epidemiology and, in particular, those in training in the subject. The authors and the editor are to be congratulated on the consistency of style throughout the book and the completeness of individual chapters.

GARY MACFARLANE $A R C$ Epidemiology Research Unit, University of Manchester.

The Faces of Homelessness in London. Jeanne Moore, David Canter, Des Stockley, and Madeline Drake. (Pp 339; 630$)$.

Aldershot: Dartmouth, 1995. ISBN 1-85521-252-8

The Salvation Army, who commissioned the original research, have developed a strateg for their London services to homeless people that draws heavily on this book's findings. The 'more subtle' findings 'will probably take more time to find their way into the consciousness of Government ministers' ( xiv). My concern is with the people considering spending $£ 30$ on the book.

Government ministers, assuming they were presented with the findings from the start, have certainly had plenty of time to digest them. It seems quite extraordinary that despite five years' lapse between fieldwork (a series of surveys of homeless people in various types of location) and publication none of the four authors reports anything that has been happening in the meantime. Not only is the reference list woefully out of date - only a handful since 1990 - but if, as the authors boast, 'some of the consequences of the research reported have already been acted upon,' it would be nice for the reader to be told what these were.

Proof reading leaves a lot to be desired. References quoted in the text are missing in the bibliography; sentences are repeated, sometimes after a few lines; tiny samples are reduced to percentages, not always credibly: how many people are $19 \%$ of 14 ?

Homelessness is an appalling problem whose solution can be assisted by data generated by surveys such as this book contains. Book buyers deserve a better deal than they get here, however.

The chapter on begging stands out as an exception. Did you know that the Strand shop-front dwellers look down on the Waterloo lot? That there are weekend beggars? That up to half of beggars, including many of those involved in prostitution, have been in care? This chapter appears not only less dogeared, but better proof-read.

BERNARD INEICHEN Lecturer in Public Health, Chelsea and Westminster Medical School, London. 